\title{
Rastreo de fibrilación auricular a través del examen físico
}

\author{
Atrial fibrillation screening by physical examination
}

Fitzmaurice D. BMJ. 2007; 335:383.

\section{Objetivo}

Evaluar si el rastreo activo de fibrilación auricular (FA) en mayores de 65 años es más efectivo que la práctica habitual y comparar el rastreo sistemático de FA con el oportunista.

\section{Diseño}

Estudio multicéntrico, controlado, aleatorizado por centro de atención y ciego con un estudio secundario dentro del grupo intervención.

Lugar

50 centros de atención primaria de Inglaterra.

\section{Pacientes}

14802 pacientes mayores de 65 años que asistían a los 50 centros de atención primaria entre 2001 y 2003.

\section{Intervención}

Los 50 centros de atención primaria fueron aleatorizados a dos subgrupos: 25 formaron parte del grupo control con ( $n=4936$ pacientes) y $25(n=9866)$. Posteriormente, fue realizada una aleatorización individual dentro del grupo intervención, donde los pacientes asignados a rastreo sistemático $(n=4933)$ fueron invitados a realizar un electocardiograma (ECG) y a los asignados a rastreo oportunista $(n=4933)$ se les tomo el pulso, indicándose un ECG sólo cuando éste era irregular. Los individuos del grupo control no recibieron rastreo activo.

\section{Medición de Resultados Principales}

Incidencia de FA.

\section{Resultados Principales}

Se analizaron los datos por intención de tratar. Luego de un año, la incidencia* de FA fue $1,63 \%$ en el grupo intervención y $1,04 \%$ en el grupo control (diferencia 0,59\%; IC95\% 0,2 a $0,98)$. El rastreo* sistemático y el oportunista detectaron incidencias similares de FA ( $1,62 \%$ vs. $1,64 \%$, diferencia $0,02 \%$; IC95\% - 0,05 a 0,05).

Tabla 1: comparación de los resultados de ambas estrategias de detección de fibrilación auricular.

\begin{tabular}{l|c|c|c|c}
\multicolumn{2}{c|}{ Grupo } & Denominador & $\begin{array}{c}\text { Nuevos } \\
\text { casos detectados }\end{array}$ & $\begin{array}{c}\text { Incidencia de } \\
\text { fibrilación } \\
\text { auricular }\end{array}$ \\
\hline No intervención & 4513 & 47 & $1,04 \%$ \\
\hline $\begin{array}{l}\text { Rastreo } \\
\text { electrocardiográfico }\end{array}$ & Oportunista & 4575 & 75 & $1,64 \%$ \\
\cline { 2 - 5 } & Sistemático & 4562 & 74 & $1,62 \%$
\end{tabular}

\section{Conclusiones}

Comparado con la práctica habitual, el rastreo activo detectó mayor número de nuevos casos de FA; sin diferencias entre los pacientes sometidos a rastreo electrocardiográfico sistemático u oportunista.

Palabras claves: rastreo, fibrilación auricular, electrocardiograma, práctica rutinaria. Key words: screening, atrial fibrillation, electrocardiogram, routine practice. Fuentes de financiamiento: no referida.

\section{Comentario}

La prevalencia de la FA varia con la edad, siendo extremadamente baja en los menores de 50 años; de 0,5\% entre los 50 y los 59 años; llegando a $5 \%$ entre los 70 y los 79 años y a $9 \%$ en los mayores de 80 años ${ }^{1}$. Por otro lado, la FA es un importante factor de riesgo para desarrollar enfermedad tromboembólica, especialmente accidente cerebrovascular ${ }^{2}$; y existe evidencia de que una vez que detectada y tratada, el riesgo de sus complicaciones asociadas disminuye dramáticamente.

Si bien las actuales guías preventivas recomiendan la toma de la tensión arterial y la auscultación cardíaca al menos una vez al año $0^{3,4}$; por el momento, no existen recomendaciones de rastrear específicamente FA, ya sea a través de la toma del pulso o de un electrocardiograma hecho en forma rutinaria.

\section{Conclusiones de la comentadora}

Si bien podemos discutir la significancia clínica de los resultados del estudio que comentamos -una detección atribuible al rastreo de $0,6 \%$, lo que implica que deben ser sometidos a rastreo 167 pacientes para poder detectar un caso adicional a los que se habrían detectado en ausencia de dicha estrategiaestos resultados avalarían la toma rutinaria del pulso, con la realización posterior de un ECG en quienes éste sea irregular. En este sentido, cabe destacar que el pulso es inevitablemente valorado durante la auscultación cardíaca y la medición de la tensión arterial; por lo que si no olvidamos realizar dichas maniobras, estaremos rastreando FA.

Mercedes Mutchinick [ Servicio de Medicina Familiar y Comunitaria Hospital Italiano de Buenos Aires. Mercedes.mutchinick@hospitalitaliano.org.ar ]

Mutchinick M. Rastreo de fibrilación auricular a través del examen físico. Evid. actual. práct. ambul; 11(6):175, Nov-Dic. 2008. Comentado de: Fitzmaurice D. Screening versus routine practice in detection of atrial fibrillation in patients aged 65 or over: cluster randomised controlled trial. BMJ 2007; 335:38. PMID: 17673732

\section{Referencia}

1. Ciapponi A. Fibrilación auricular. Capítulo 145. Publicado en "Medicina Familiar y Practica Ambulatoria". Editores Rubinstein A, Terrasa S y col. 2da edición, Buenos Aires, Médica Panamericana, 2006. pp 1170-1185.

2. Wolf $\mathrm{P}$ y col. Atrial fibrillation as an independent risk factor for stroke: The Framingham study. Stroke 1991; 22:983-8.

3. Ciapponi A. Resumen de la Guía de cuidados preventivos de la Fuerza de Tareas de Estados Unidos (primera entrega) Evid.actual.pract.ambul 2005;8: 179-182.

4. Ciapponi A. Resumen de la Guía de cuidados preventivos de la Fuerza de Tareas de Estados Unidos (segunda entrega). Evid. actual. práct.ambul; 9(1): 26-30, Ene-Feb 2006. 